


$161-83$

\title{
vivienda en las afueras de París
}

CLAUDE PARENT, arquitecto 

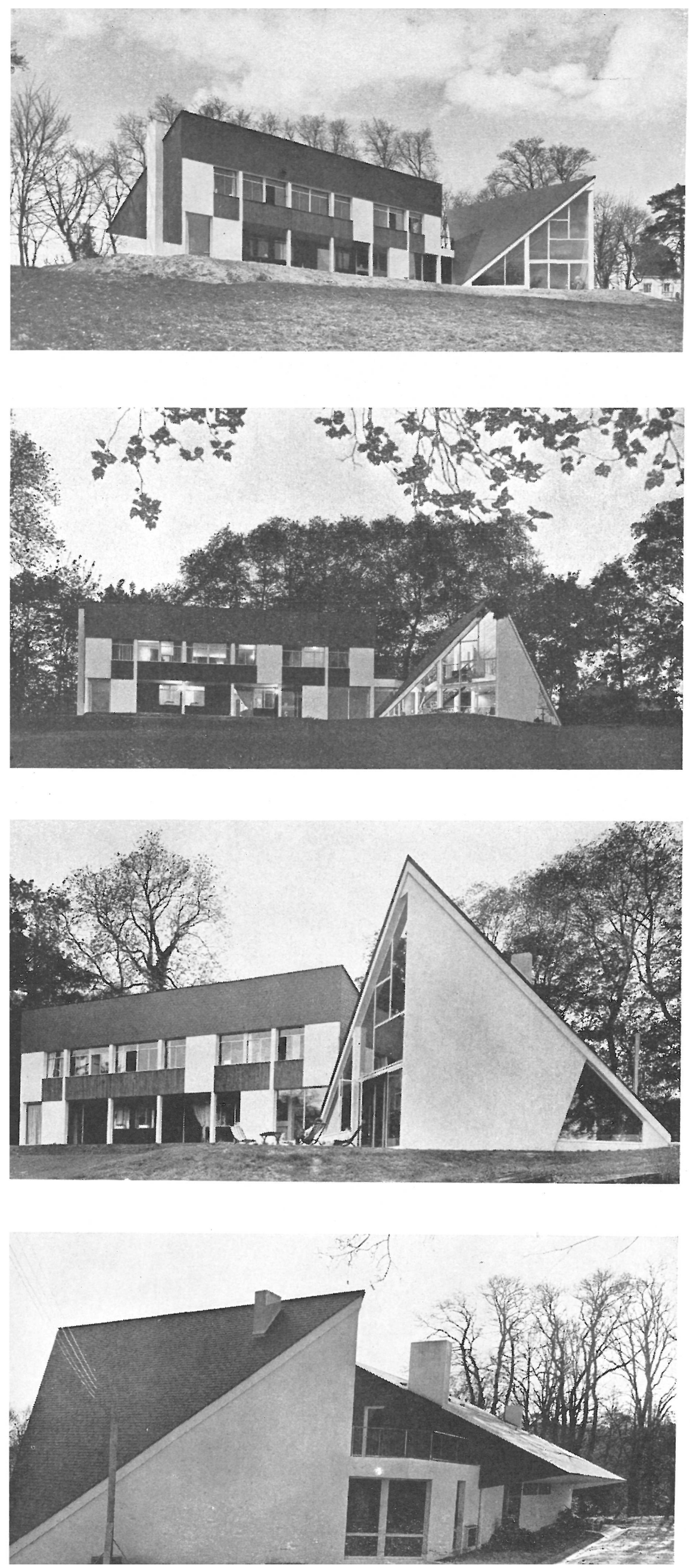

Esta casa, destinada para habitación permanente de una familia joven - compuesta de marido, mujer y tres hijos-, aparece como una residencia verdaderamente importante en cuanto a su apariencia y distribución que responde al siguiente programa: cinco dormitorios con los servicios correspondientes, gran zona de recepción, amplio vestíbulo, sótano e instalaciones y almacenes.

Situada sobre un terreno de 20.000 metros cuadrados con suave pendiente y plantado de hermosos árboles, articula sus dos volúmenes principales - cubiertos con pizarra-en diversos niveles, que prestan variedad al interior.

Las características plásticas del exterior vienen expresadas por las grandes y acusadas pendientes de los faldones de cubierta, que descienden casi hasta el suelo como grandes triángulos azulados de agudos vértices. La distinta configuración y composición de estos planos oblicuos, determina y define las dos zonas de que se compone el complejo arquitectónico: cubierta a dos aguas para la parte semipública o recepción y cubierta a una sola agua para la zona íntima o de dormitorios. Esta segunda es normal y sistemática, en dos alturas, mientras que la primera presenta la variedad de una distribución más libre, en tres niveles, dos con una diferencia de 80 centímetros $\mathrm{y}$ otra planta elevada - como entresuelo-a la que se asciende por una fina escalera metálica con peldaños de madera.

\section{planta de cubiertas}

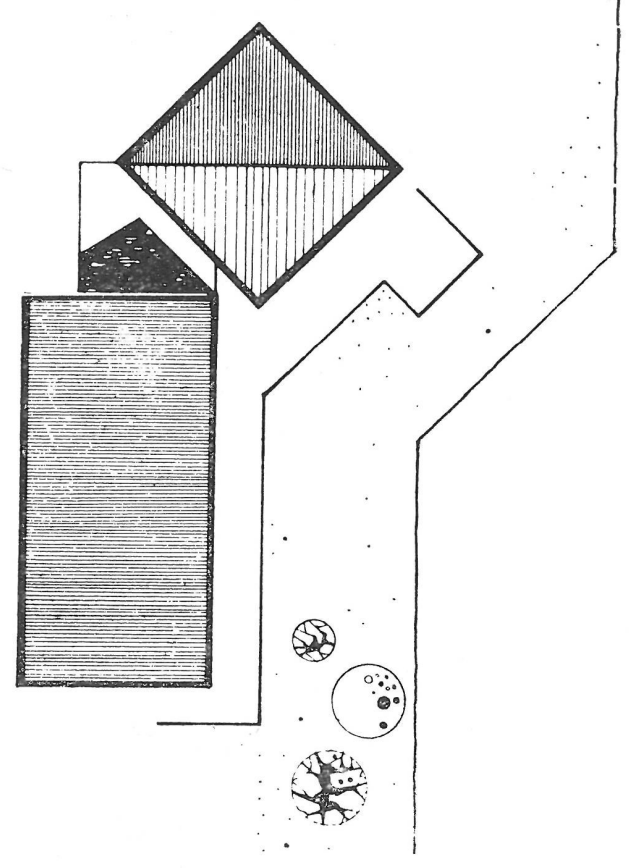




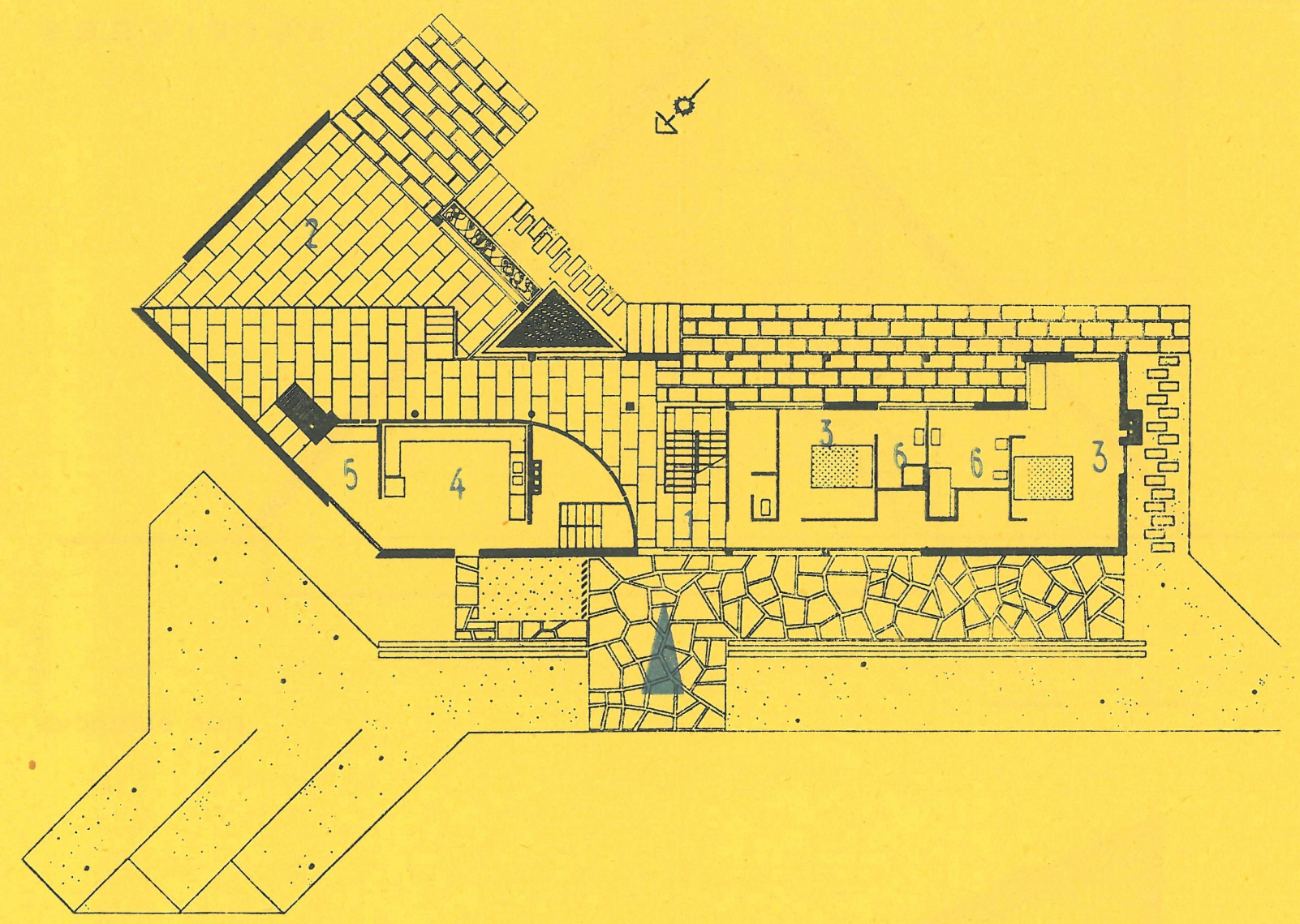

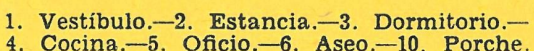

planta baja

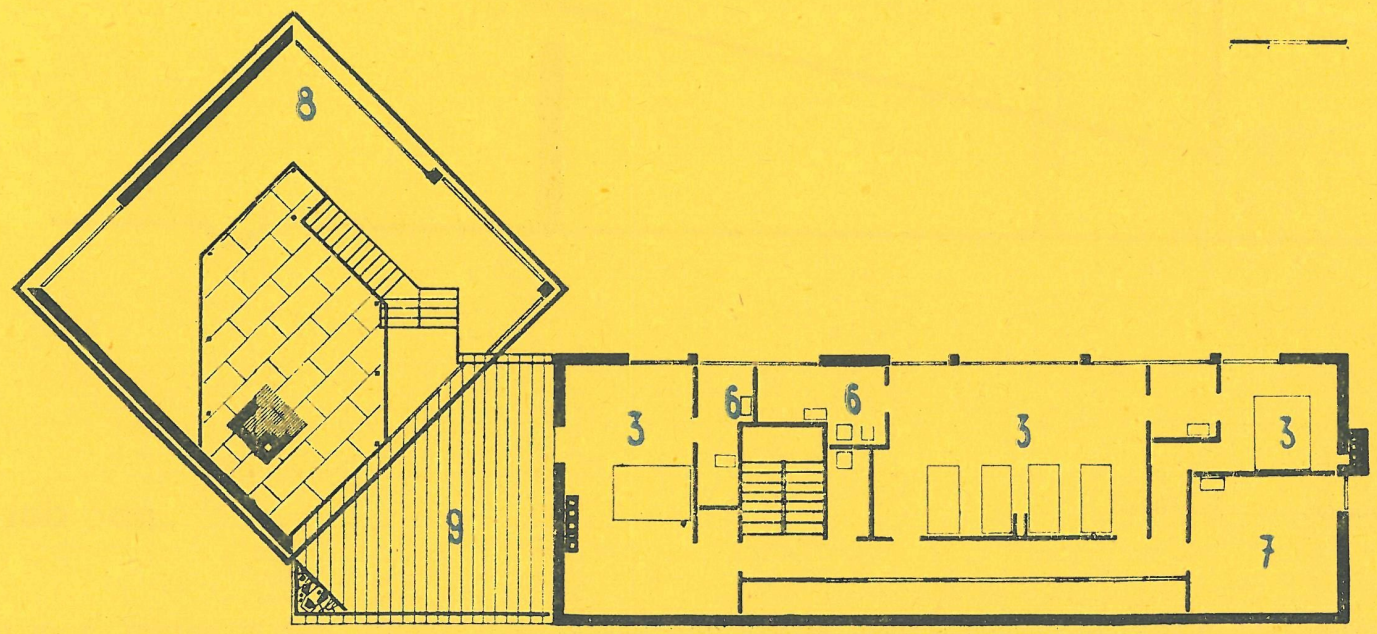

3. Dormitorio.-6. Aseo.-7. Juegos.-8. Par-

te alta estancia.-9. Terraza.

planta principal 


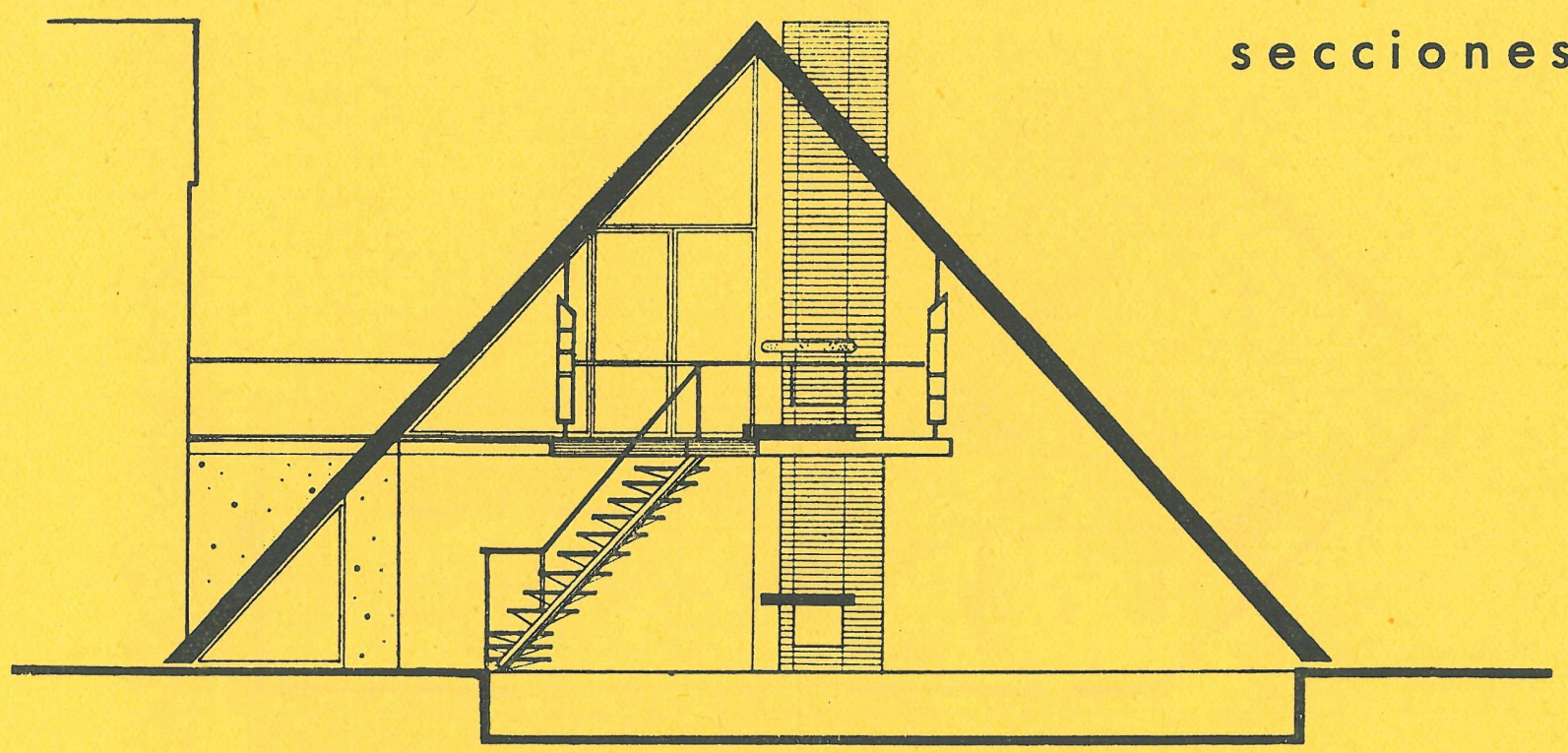

por estancia

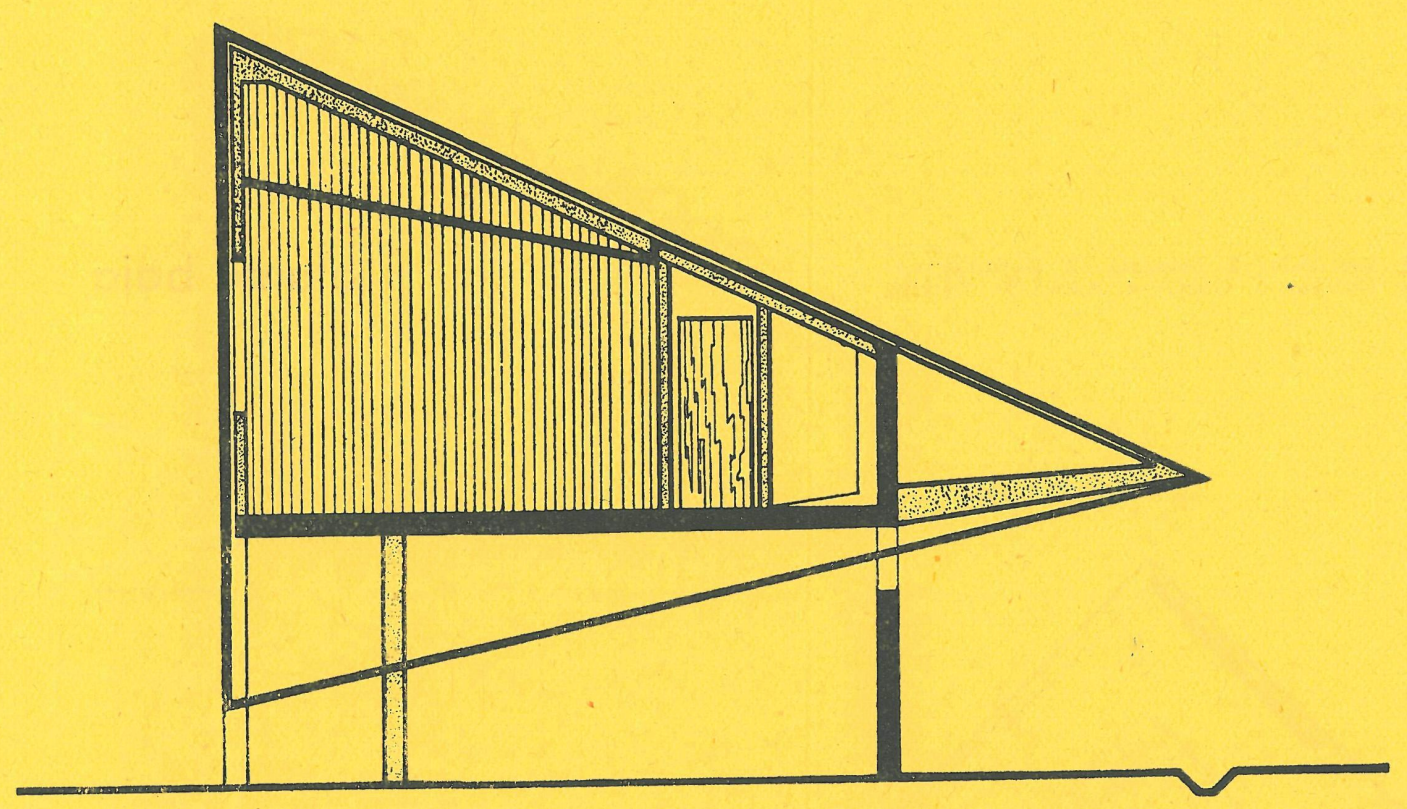

$\therefore$ - =

por dormitorios

Desde esta planta se accede a una terraza descubierta, a occidente, que comunica, a su vez, con el cuerpo de edificio destinado a dormitorios.

Parte el estudio arquitectónico de un juego de volúmenes cuya articulación se lleva a cabo sobre el hall de entrada-con estilizada escalera de barandilla metálica, zanca de hormigón y peldaños de madera-de transparencia cuidada en grado sumo, y sobre los servicios (cocina, oflcio, despensa y bajada al sótano), de la zona representativa, cubiertos con terraza. 

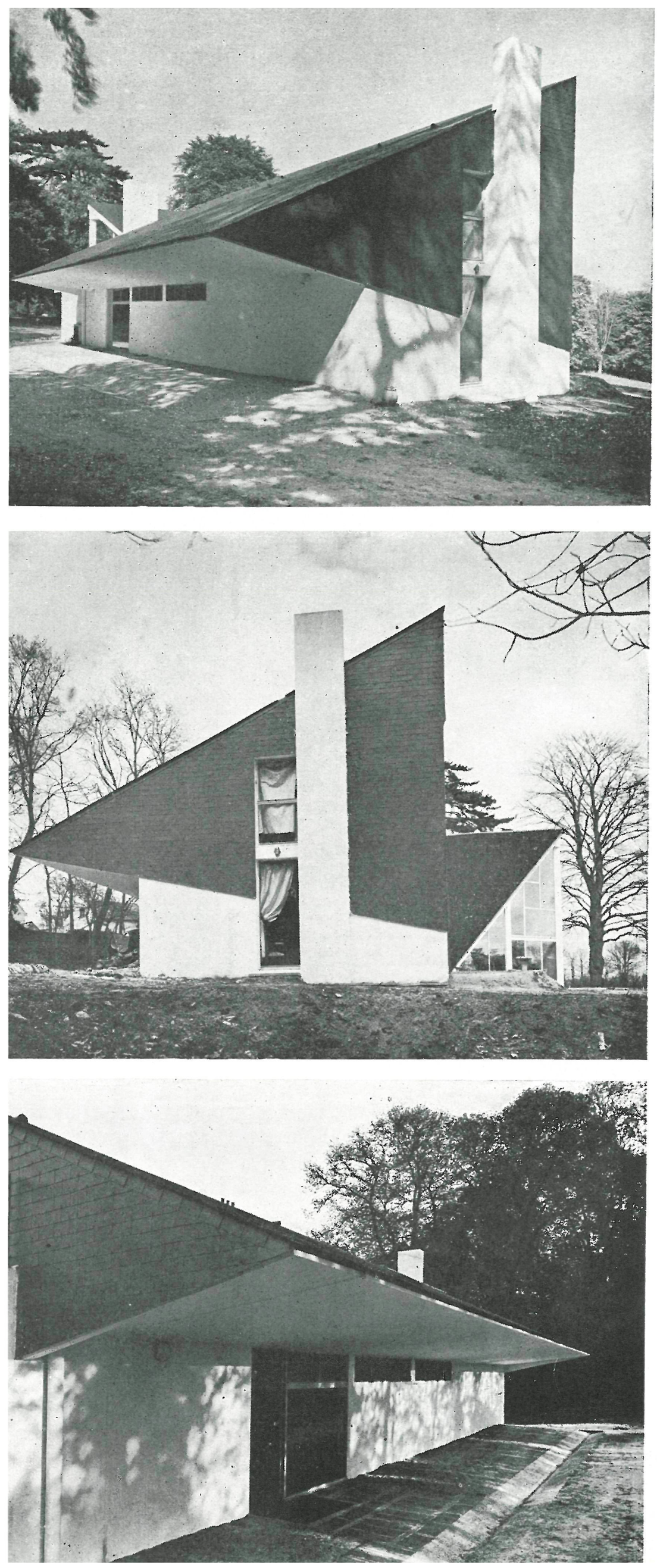

Las distintas vistas muestran el juego de pendientes de los faldones de cubierta.

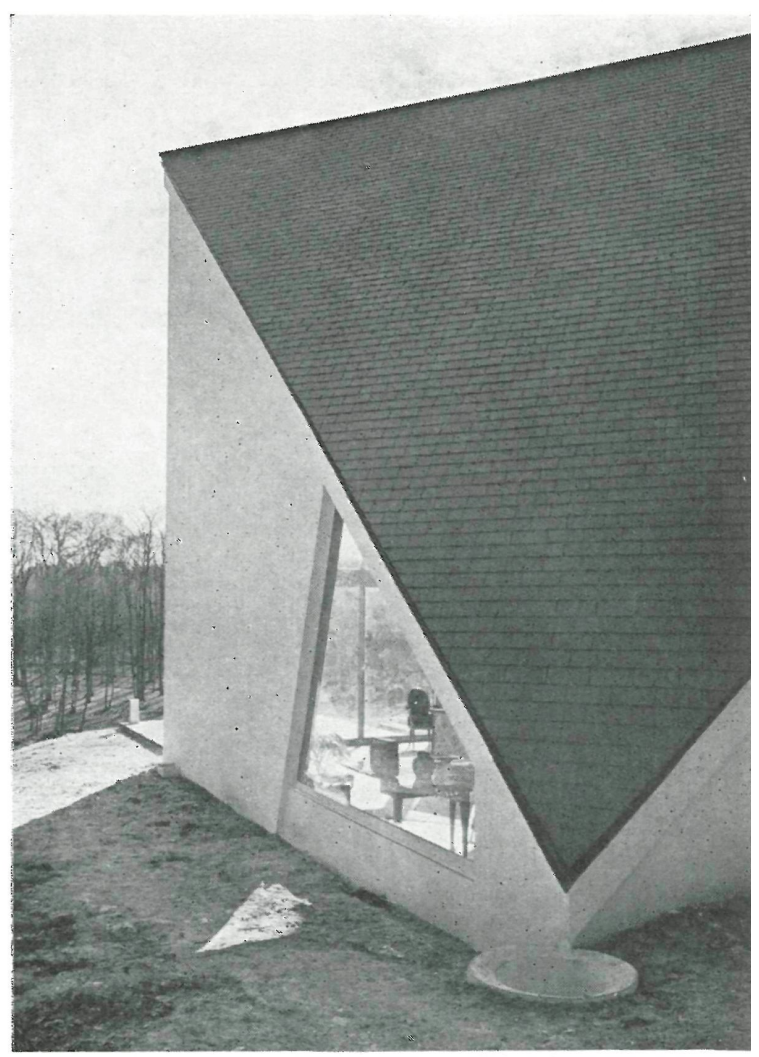



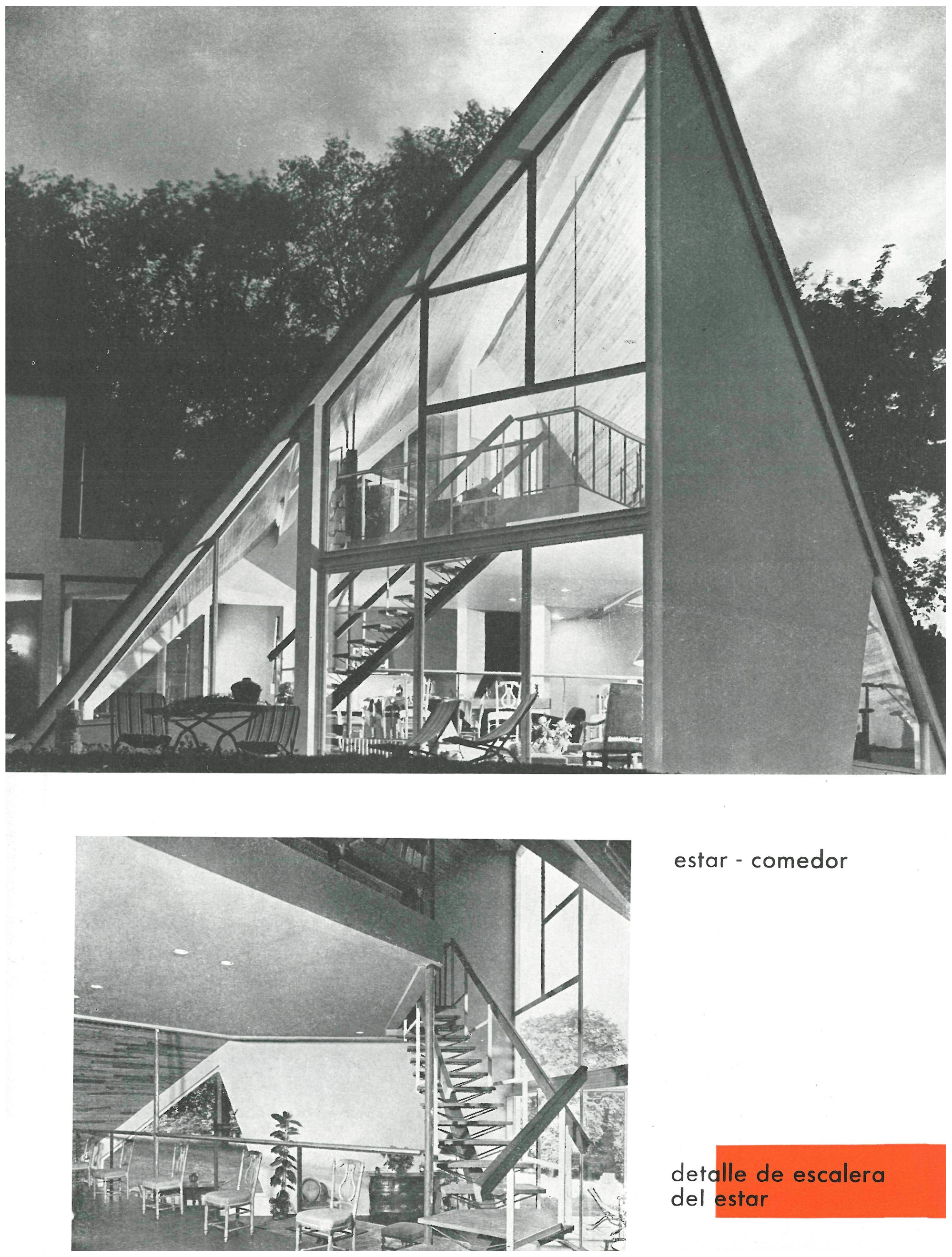

estar - comedor

detalle de escalera del estar 

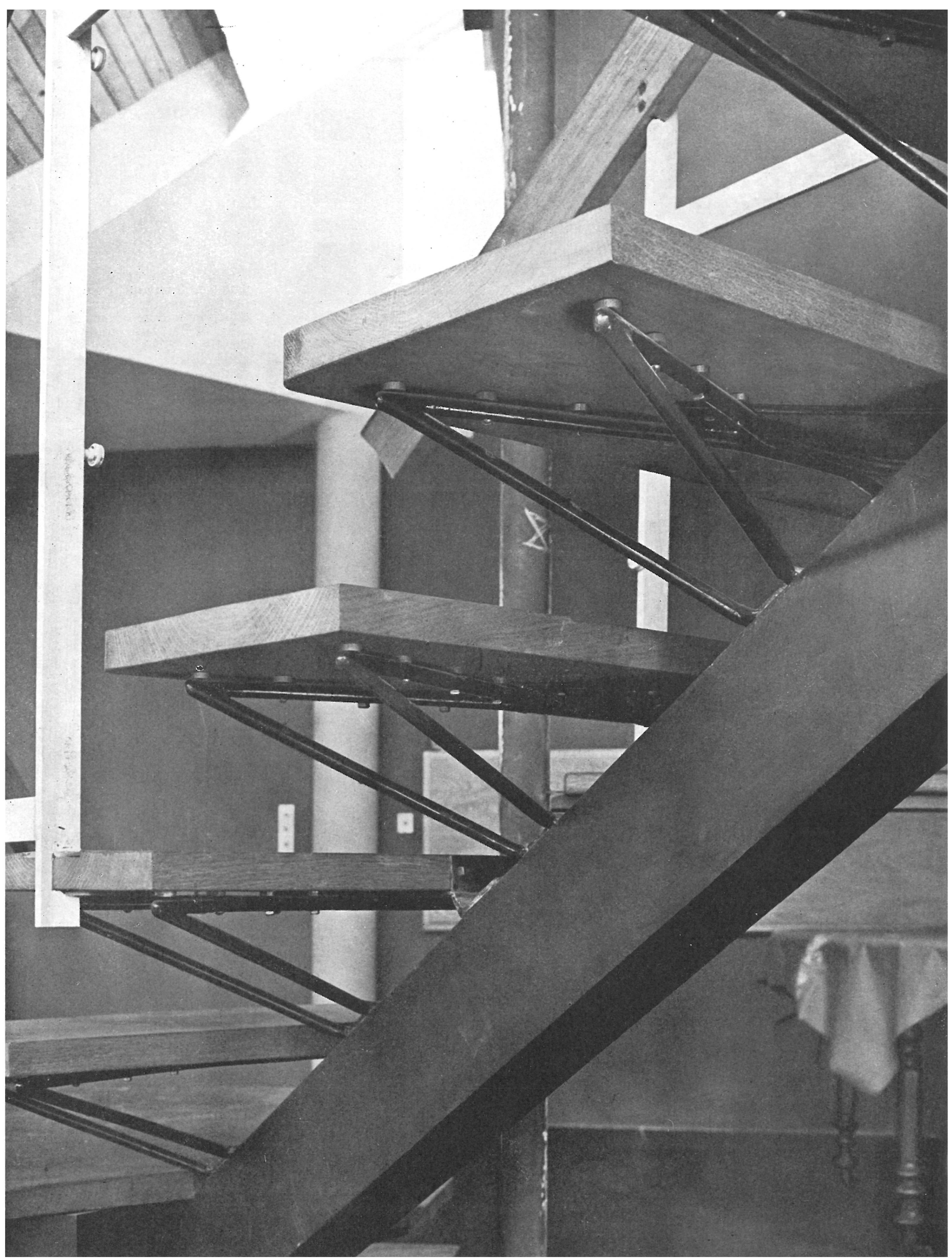

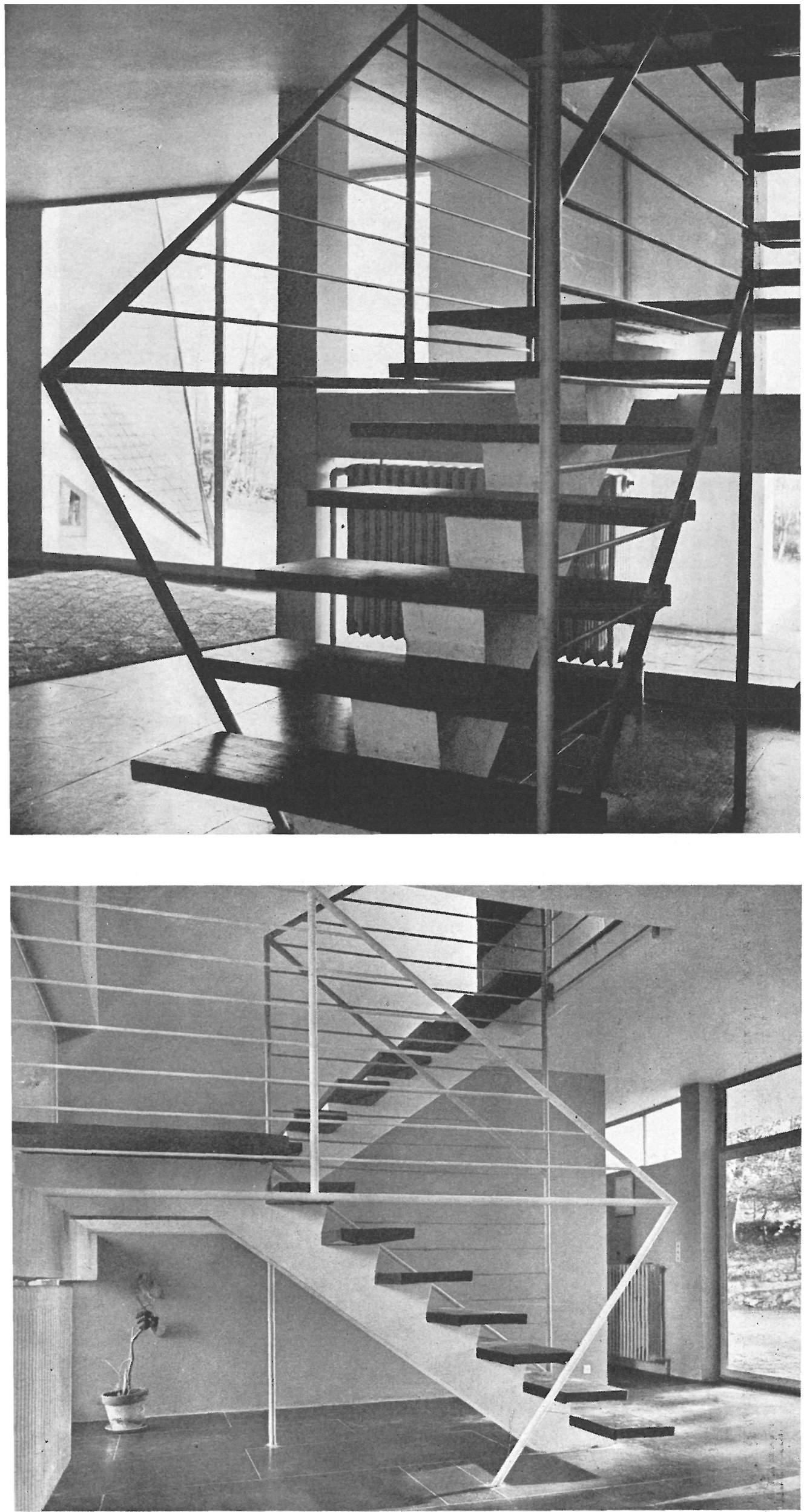

\section{escalera \\ vestíbulo}

Con objeto de que las aguas de lluvia que recogen los faldones de la cubierta conserven la máxima pureza, se han suprimido todo tipo de canalones de zinc, de modo que dichos faldones triangulares viertan directamente sobre depósitos troncocónicos de hormigón, sobre un arroyo o sobre una lámina de agua triangular con misión ornamental y reflectante.

Los pavimentos son de losas de pizarra pulimentada en el interior y piezas rectangulares de labra semibasta en el exterior. Los materiales fundamentales que exornan la vivienda (pizarra, madera y paños encalados) prestan al conjunto una coloración severa que sirve para subrayar más todavía el citado contraste.

La estructura resistente (vigas y pilares) es totalmente de hormigón armado, que se deja visto, cubierto con una capa de color, en pilares del porche anterior, viguería del salón de estancia y techo inclinado del voladizo posterior, destinado a garaje.

El contraste de que hemos hablado en cuanto al exterior, se manifiesta igualmente en la agradable disparidad existente entre el es tilo arquitectónico avanzado de la casa y los muebles de estilo clásico que se ven en la sala de estar, la cual abre franca y pródigamente su fachada triangular acristalada hacia el jardín. Durante la noche, estas fachadas lucen fantásticamente por los diversos y rasgados huecos de formas distintas que transparentan, a voluntad, la vida interior $\mathrm{y}$, a la vez, ponen todas las estancias en comunicación amplia con la naturaleza. 